Santa Clara University

Scholar Commons

Psychology

College of Arts \& Sciences

5-19-2020

\title{
Online communication and dating relationships: Effects of decreasing online communication on feelings of closeness and relationship satisfaction
}

\author{
Kieran T. Sullivan \\ Santa Clara University, ksullivan@scu.edu \\ Jessica Riedstra \\ Brenda Arellano \\ Bonnie Cardillo \\ Vanessa Kalach
}

See next page for additional authors

Follow this and additional works at: https://scholarcommons.scu.edu/psych

Part of the Psychology Commons

\section{Recommended Citation}

Sullivan, K. T., Riedstra, J., Arellano, B., Cardillo, B., Kalach, V., \& Ram, A. (2020). Online communication and dating relationships: Effects of decreasing online communication on feelings of closeness and relationship satisfaction: Journal of Social and Personal Relationships. https://doi.org/10.1177/ 0265407520924707

Copyright (C) 2020 SAGE Publications. Reprinted with permission. The final publication is available at https://doi.org/10.1177/0265407520924707.

This Article is brought to you for free and open access by the College of Arts \& Sciences at Scholar Commons. It has been accepted for inclusion in Psychology by an authorized administrator of Scholar Commons. For more information, please contact rscroggin@scu.edu. 


\section{Authors}

Kieran T. Sullivan, Jessica Riedstra, Brenda Arellano, Bonnie Cardillo, Vanessa Kalach, and Amrita Ram 
Online Communication and Dating Relationships: Effects of Decreasing Online Communication on Feelings of Closeness and Relationship Satisfaction

\author{
Kieran T. Sullivan \\ Jessica Riedstra \\ Brenda Arellano \\ Bonnie Cardillo \\ Vanessa Kalach \\ Amrita Ram \\ Santa Clara University
}

\begin{abstract}
Author Note
Correspondence concerning this article should be addressed to Kieran T. Sullivan, Department of Psychology, Santa Clara University, Santa Clara, CA, 95124. ksullivan@ @scu.edu
\end{abstract}




\begin{abstract}
The purpose of this study was to examine the effects of online communication on feelings of closeness and relationship satisfaction using an experimental design, and to test whether these effects varied based on participants' attitudes about online communication. Individuals in dating relationships were randomly assigned to two 48-hour conditions: communication as usual or refraining from online communication. Participants who reported that online communication was important for their dating relationships reported lower satisfaction and closeness after decreasing their online communication; there were no between-group differences among participants who reported relatively low importance. Thus, it appears that online communication has a positive effect on relationship satisfaction and feelings of closeness, but only for those who consider online communication to be important.
\end{abstract}

Keywords: intimate relationships, online communication, online attitudes, relational closeness, relationship satisfaction 
Online Communication and Dating Relationships: Effects of Decreasing Online Communication on Feelings of Closeness and Relationship Satisfaction

Advancements in technology over the past two decades have led to significant and farreaching changes in how people communicate with intimate partners (Hall \& Baym, 2012). Given the importance of intimate relationships for life satisfaction (e.g., Gustavson, Røysamb, Borren, Torvik, \& Karevold, 2016), mental health (e.g., Whitton \& Whisman, 2010), and physical health (e.g., Holt-Lunstad, Smith, \& Layton, 2010), and the ubiquity of online communication, how these changes in communication affect intimate relationships is a critical question.

A growing body of research has shed light on the role online communication plays in intimate relationships. A number of empirical studies suggest that online communication can positively affect relationships, supplementing and even augmenting more traditional forms of communication (e.g., Baym, Zhang, \& Lin, 2004). Indeed, online communication is associated with feelings of closeness (Ledbetter, 2015) and relationship satisfaction (Hall \& Baym, 2012) with personal relationships. In dating partners, online communication is associated with increased personal self-disclosure, which in turn is associated with relationship intimacy and quality of communication - even after controlling for the contributions of face-to-face interactions (Boyle and O'Sullivan, 2016).

In contrast, some evidence suggests that the use of online communication may be detrimental to personal relationships. Personal messaging has been found to be negatively associated with relationship satisfaction in personal and family relationships (e.g., GoodmanDeane et al., 2016). Further, experimental data show that the mere presence of a mobile device negatively affects the development of intimacy and closeness in dyads (Przybylski \& Weinstein, 
2013). In a large $(n=1300)$ longitudinal study, Chesley (2005) found that use of cell phones over time is associated with work stress spillover into family life and decreased family satisfaction.

These mixed findings suggest a more nuanced view is necessary to understand the effects of online communication on intimate relationships (Shklovski et al., 2004). Ledbetter and colleagues have presented compelling evidence that attitude about communicating online is a key moderator for understanding variance in the associations between online communication and relationships (Ledbetter, et al., 2011; Ledbetter \& Mazer, 2014; Ledbetter, 2015). For example, they found that Facebook communication predicted greater relational interdependence when participants held positive attitudes about the relational value of online communication (Ledbetter \& Mazer, 2014), suggesting that online communication has positive effects on relationships, but only for some individuals.

Even as more nuanced models are being developed and tested, our understanding of the effects of online communication is limited by the cross-sectional designs used in the majority of research (cf. Chesley, 2005). Thus, it remains unclear, for example, whether relatively high amounts of time spent communicating online makes individuals feel closer to their partners or whether greater closeness leads individuals to spend more time communicating with their partners online.

\section{Purpose}

The purpose of the present study is to determine if changes in online communication affect relationship closeness and satisfaction - taking attitudes about online communication into account - using an experimental design. Specifically, we compared relationship satisfaction and feelings of closeness following a 2-day period wherein some participants were instructed to 
communicate online with their partners as usual (control condition) and some were instructed to refrain from online communication with their partner (experimental condition; a design similar to that used in Sheldon, Abad, \& Hinsch, 2001). College students in dating relationships were randomly assigned to conditions after providing self-report data about relationship satisfaction, closeness, and the importance of online media for communicating with their partners.

We consider competing models: one in which online communication serves a positive function (positive effect model) wherein reductions in online communication lead to lower closeness and satisfaction, compared to the control group, and one in which it serves a negative function (negative effect model) wherein reductions in online communication lead to greater closeness and satisfaction, compared to the control group. Based on past findings by Ledbetter and colleagues (e.g., Ledbetter \& Mazer, 2014) we predict that any effects will be moderated by attitudes about online communication such that effects will be more positive (or less negative) among participants who place greater importance on online communication.

\section{Participants}

\section{Method}

Students enrolled in general psychology classes were recruited via a psychology department participation pool. Eligible participants were in dating relationships that were not long distance $(n=128)$. Of these, $55 \%$ were women and $45 \%$ were men and $125(98 \%)$ were in heterosexual relationships. Participants identified as Caucasian (58\%), Asian-American (21\%), Latino/a (18\%), and African-American (3\%). The mean age of participants was 19.14 years (SD $=1.09$; ranging from 17 to 21 years of age) and the mean relationship length was 15.18 months $(S D=14.49 ;$ ranging from 1 month to 7 years $)$. All participants were unmarried and only one participant was living with her dating partner. Participants received course credit for participation. 


\section{Procedure}

Before beginning the study, institutional review board approval was obtained. Eligible students were invited to sign up for two lab sessions that were 48 hours apart and informed that, if they signed up for the study, they might be asked to refrain from online communication with their dating partners in that 48-hour interval. At the first lab session, participants read an informed consent form that explained all aspects of the study and reiterated the experimental conditions. Participants filled out a series of online questionnaires and were randomly assigned to an experimental or control group. Participants in the experimental group were given instructions to refrain from online communication with their dating partners (i.e., texting, personal messaging, posting on partners' social network sites, etc.) for the next 48 hours (they were allowed to send a direct message to inform their dating partner of these conditions before they left the lab). Participants in the control condition were told they should continue to communicate as usual with their dating partner. At Time 2, all participants filled out relationship questionnaires again and participants in the experimental condition were asked about compliance and the experience of refraining from online communication.

\section{Questionnaires}

Relationship closeness. Relationship closeness was assessed using the 7-item relationship closeness questionnaire (Vangelisti \& Caughlin, 1997). An example item is "I feel connected to my partner." Participants responded to each item on a scale of 1 (strongly disagree) to 4 (strongly agree); total scores range from 1 to 28 . Coefficient alpha was .73

Relationship satisfaction. Relationship satisfaction was assessed using the 4-item Couples Satisfaction Index (CSI-4, Funk \& Rogge, 2007). An example item is "Please indicate the degree of happiness, all things considered, of your relationship." Total scores range from 4 to 


\section{Coefficient alpha was .83}

Time spent communicating online. Time spent was assessed at Time 1 with one question "In the past week, on average, approximately how much time PER DAY did you spend communicating with your dating partner ONLINE (e.g., texts, emails, Facebook messaging, SnapChat, etc.)?” Participants selected one of the following responses: $<10 \mathrm{~min}, 10-30 \mathrm{~min}, 31$ $60 \mathrm{~min}, 1-2 \mathrm{hrs}, 2-3$, or 3-4 hrs.

Importance of online communication. This was assessed at Time 1 by adapting the 7item social connection scale of the Online Attitudes Questionnaire (OAQ; Ledbetter, 2009) to refer specifically to dating partners. An example item is: "If I couldn't communicate online, I would feel 'out of the loop' with my dating partner" Participants responded to each item on a scale of 1 (strongly disagree) to 7 (strongly agree); total scores range from 7 - 49. Coefficient alpha was .89 .

\section{Preliminary Analyses}

Descriptive statistics for all Time 1 variables can be seen on Table 1 along with independent-samples t-tests; no between group differences were found at Time 1 . At Time 2 the manipulation was checked by asking participants in the experimental group how often they used online communication with their dating partner in the past two days on a scale of 1 (a lot less than usual) to 5 (a lot more than usual). Seven participants in the experimental condition $(n=59)$ reported that they used online communication as much or more than they typically do in the past two days; their results were not included in the longitudinal analyses.

\section{Results}

Correlations among all variables can be seen in Table 2. The relationship measures were positively correlated with one another and negatively correlated with the importance of online 
communication. Time spent communicating online was not related to satisfaction nor closeness, but was related to importance.

To assess whether the manipulation affected closeness and satisfaction, and whether attitudes about the importance of online communication moderated any impact of decreasing online communication, two hierarchical linear regressions were conducted (see Table 3). First, the $\mathrm{T} 1$ relationship variable (i.e., closeness or satisfaction), condition, and importance were entered as a block (Step 1), then the interaction term was entered (Step 2). ${ }^{1}$ All continuous variables were centered for these analyses.

Step 1 was statistically significant when predicting Time 2 closeness and Time 2 relationship satisfaction. There was a positive main effect for the Time 1 relationship measures and a negative main effect for the importance of online communication, such that the more important online communication was, the lower closeness and satisfaction were at Time 2.

In Step 2, there was a main effect of initial closeness/relationship satisfaction but no main effect of importance. There was a statistically significant interaction between condition and importance for Time 2 closeness and a marginal effect for Time 2 relationship satisfaction. Simple slopes analyses revealed that condition affected closeness at high, $\mathrm{t}(50)=4.02, \mathrm{p}<.001$, but not low levels of importance $\mathrm{t}(50)=-.22, \mathrm{p}=\mathrm{ns}$ (see Figure 1 ). That is, participants who reduced time spent communicating online reported significantly lower closeness - after controlling for Time 1 closeness - compared to participants who communicated as usual, but only among participants who reported that online communication was important for their relationship. Likewise, condition affected relationship satisfaction at high, $\mathrm{t}(50)=3.27, \mathrm{p}<.01$, but not low importance t $(50)=-.68$ (see Figure 1). Again, for participants high in importance, reducing online communication led to lower relationship satisfaction scores compared to 
participants who communicated as usual.

\section{Discussion}

\section{Summary and Implications of Findings}

Cross-sectionally, self-reported time spent communicating online was only weakly associated with closeness, and not significantly associated with relationship satisfaction. The importance participants placed on online communication was negatively related to closeness and satisfaction, but this finding should be interpreted in light of the significant interaction between condition and importance. Experimentally reducing time spent did not directly affect closeness or satisfaction, but did negatively affect closeness and satisfaction among participants who considered online communication to be relatively important. These findings are most consistent with the positive effects model, at least among partners for whom communicating online is important. Findings provide no support for the negative effects model.

These findings are consistent with previous studies that found that the association between online communication and relational closeness was moderated by attitudes in personal relationships (Ledbetter et al., 2011; Ledbetter \& Mazer, 2014) and provide experimental evidence that changes in the use of online communication causes changes in satisfaction and closeness, but only for some individuals. In other words, online communication does not affect all relationships in the same way, and any beneficial effect is more likely when partners value this medium of communication as a way to stay connected with one another.

\section{Limitations}

This experimental design is a relatively new approach and most certainly has limitations as to how well it captures the constructs of interest and their relationships with one another. This, along with the paucity of experimental research, makes it prudent to replicate these results to 
increase confidence in the findings. Online communication was defined broadly; future studies would benefit by examining specific constructs (e.g., specific media) and more sophisticated models (e.g., modality switching; Fox \& McEwan, 2017). Additionally, we studied individuals; studying couples would allow for dyadic analyses. Finally, the 48-hour period may have been too short to detect significant main effects; use of a longer period may reveal additional effects.

\section{Conclusions and Suggestions for Future Research}

This study suggests that online communication affects relationships positively, but only for some people. Previous cross-sectional studies have identified other factors that might moderate the effects of online communication on relationships, including pressure to respond to online messages (Hall \& Baym, 2012) and individual differences in personality and attachment style (e.g., Hu, Kim, Siwek, \& Wilder, 2017). Future experimental research may benefit by examining these variables.

Understanding how technological advancements affect intimate relationships involves significant design challenges. Foremost, perhaps, are ethical and/or practical considerations (e.g., manipulating relationship satisfaction) and participants' unwillingness to comply (e.g., refraining from online communication for significant periods of time). Anecdotally, investigators were told a number of times that eligible students did not sign up for the study because they did not want to risk going 48 hours without using online communication with their dating partners. Longitudinal studies, such as Chesley (2005), are useful for shedding light on causation when experimental designs are not possible. Intergenerational studies may also help, although it would be difficult to parse out cohort effects in this type of design.

Nevertheless, this study underscores the importance of employing designs that interrogate directionality in associations between online communication and satisfaction and closeness, as 
well as interpersonal and intrapersonal factors that may moderate or mediate the effects of online communication on relationships. 


\section{References}

Baym, N., Zhang, Y., \& Lin, M. (2004). Social interactions across media: Interpersonal communication on the internet, telephone, and face-to-face. New Media \& Society, 6, 299-318. doi: 10.1177/1461444804041438.

Boyle, A. M., \& O’Sullivan, L. F. (2016). Staying Connected: Computer-Mediated and Face-toFace Communication in College Students' Dating Relationships. Cyberpsychology, Behavior, and Social Networking, 19, 299-307. doi:10.1089/cyber.2015.0293.

Chesley, N. (2005). Blurring boundaries? Linking technology use, spillover, individual distress, and family satisfaction. Journal of Marriage and Family, 67, 1237-1248. doi: 10.1111/j.1741-3737.2005.00213.

Fox, J., \& McEwan, B. (2017). Distinguishing technologies for social interaction: The Perceived Social Affordances of Communication Channels Scale. Communication Monographs, 84, 298-318. doi: 10.1080/03637751.2017.1332418

Funk, J., \& Rogge, R. (2007). Testing the ruler with item response theory: Increasing precision of measurement for relationship satisfaction with the Couples Satisfaction Index. Journal of Family Psychology, 21, 572-583. doi:10.1037/0893-3200.21.4.572.

Gustavson, K., Røysamb, E., Borren, I., Torvik, F A., \& Karevold, E. (2016). Life satisfaction in close relationships: Findings from a longitudinal study. Journal of Happiness Studies, 17, 1293-1311. doi: 10.1007/s10902-015-9643-7

Goodman-Deane, J., Mieczakowski, A., Johnson, D., Goldhaber, T., Clarkson, P. J. (2016). The impact of communication technologies on life and relationship satisfaction. Computers in Human Behavior, 57, 219-229. doi: doi.org/10.1016/j.chb.2015.11.053

Hall, J., \& Baym, N. (2012). Calling \& texting (too much): Mobile maintenance expectations, 
(over)dependence, entrapment, and friendship satisfaction. New Media \& Society 14, 316-331. doi: 10.1177/1461444811415047

Holt-Lunstad, J., Smith, T. B., \& Layton, J. B. (2010). Social relationships and mortality risk: A meta-analytic review. PLoS Medicine, 7, e1000316. doi: 10.1371/journal.pmed.1000316

Hu, X., Kim, A., Siwek, N., \& Wilder, D. (2017). The Facebook paradox: Effects of Facebooking on individuals' social relationships and psychological well-being. Frontiers in Psychology, 8. doi: 10.3389/fpsyg.2017.00087.

Ledbetter, A. M. (2009). Measuring online communication attitude: Instrument development and validation. Communication Monographs 76: 463-486. doi: 10.1080/03637750903300262.

Ledbetter, A. M. (2015). Media multiplexity theory: technology use and interpersonal tie strength. In D. O. Braithwaite, \& P. Schrodt (Eds.), Engaging theories in interpersonal communication (2nd ed., pp. 357-370). Thousand Oaks, CA: Sage.

Ledbetter, A. M., \& Mazer, J. P. (2014). Do online communication attitudes mitigate the association between Facebook use and relational interdependence? An extension of media multiplexity theory. New Media \& Society, 16, 806-822.

doi:10.1177/1461444813495159.

Ledbetter, A. M., Mazer, J., DeGroot, J., Mao, Y., Meyer, K., \& Swafford, B. (2011). Attitudes toward online social connection and self disclosure as predictors of Facebook communication and relational closeness. Communication Research, 38, 27-53. doi: $10.1177 / 0093650210365537$.

Sheldon, K., Abad, N., Hinsch, C. (2011) A two-process view of Facebook use and relatedness need-satisfaction: Disconnection drives use, and connection rewards it. Journal of 
Personality and Social Psychology, 100, 766-775. doi: 10.1037/a0022407.

Shklovski, I., Kraut, R., \& Rainie, L. (2004). The internet and social participation: contrasting cross-sectional and longitudinal analyses. Journal of Computer-Mediated Communication, 10, 00. doi: 10.1111/j.1083-6101.2004.tb00226.

Whitton, S.J. \& Whisman, M.A. (2010). Relationship Satisfaction Instability and Depression. Journal of Family Psychology, 24, 791-794. doi: 10.1037/a0021734. 
${ }^{1}$ Analyses were also run controlling for self-reported time spent online; the pattern of results was the same. 
Table 1

Descriptive Statistics and Between-groups t Tests for Time 1 variables

\begin{tabular}{ccccc}
\hline Variable & $M$ & $S D$ & $t$ & $p$ \\
\hline Feelings of Closeness & & & & \\
Control Group $^{1}$ & 23.32 & 2.97 & 1.65 & 0.13 \\
Experimental Group $^{2}$ & 23.76 & 2.84 & & \\
& 22.90 & 3.03 & & \\
Relationship Satisfaction & 18.57 & 4.49 & 1.19 & 0.24 \\
$\quad$ Control Group & 19.05 & 4.08 & & \\
Experimental Group & 18.11 & 4.84 & & \\
& & & & \\
& 4.02 & 1.69 & -0.11 & 0.92 \\
Time Spent Communicating Online ${ }^{3}$ & 4.00 & 1.68 & & \\
$\quad$ Control Group & 4.03 & 1.71 & & \\
Experimental Group & & & & \\
& 20.26 & 9.75 & 0.54 & 0.59 \\
Importance of Online Communication & 20.73 & 9.82 & & \\
$\quad$ Control Group & 19.80 & 9.73 & & \\
Experimental Group & & & &
\end{tabular}

${ }^{1} N=63 ;{ }^{2} N=65 ;{ }^{3}$ A score of 4.0 indicates $1-2$ hours communicating online with partner each day 
ONLINE COMMUNICATION AND DATING RELATIONSHIPS

Table 2

Pearson Product-moment Correlations Among All Variables

\begin{tabular}{|c|c|c|c|c|}
\hline Variables & 1 & 2 & 3 & 4 \\
\hline 1 Feelings of Closeness to Partner & 1.00 & & & \\
\hline 2 Relationship Satisfaction & $.72 \leftrightarrow$ & 1.00 & & \\
\hline 3 Time Spent Communicating Online & .08 & .15 & 1.00 & \\
\hline 4 Importance of Online Communication & $-.32 \leftrightarrow$ & $-.31 \leftrightarrow$ & $.33 \leftrightarrow$ & 1.00 \\
\hline
\end{tabular}

Note. $* \mathrm{p}<0.05 ; *{ }^{*} \mathrm{p}<0.01 ; * *{ }^{* *}<0.001$ 
Table 3

Hierarchical Linear Regression Analyses of Importance and Condition on Relationship Satisfaction and Feelings of Closeness

\begin{tabular}{llllllcc}
\hline & & & & \multicolumn{3}{c}{ Adjusted } \\
Model & B & SE B & $\beta$ & F & r2 & $\Delta \mathrm{R}^{2}$ \\
\hline
\end{tabular}

Time 2 Feelings of Closeness

Step 1

Time 1 Feelings of Closeness

Condition

Importance

Step 2

Time 1 Feelings of Closeness

Condition

Importance

Importance $\mathrm{x}$ Condition

$\begin{array}{ccc}0.40 & 0.11 & 0.31 \\ -1.08 & 0.64 & -0.14 \\ -0.07 & 0.03 & -0.19\end{array}$

$$
9.65 \cdots 0.18
$$

$-0.14$

$-0.19$

\section{$9.65+0.18$}

$\begin{array}{lll}0.41 & 0.11 & 0.32 \\ 2.10 & 1.42 & 0.28 \\ 0.00 & 0.05 & 0.01 \\ & & \\ -0.16 & 0.06 & -0.50\end{array}$

Time 2 Relationship Satisfaction

Step 1

Time 1 Relationship Satisfaction

Condition

Importance

$\begin{array}{cc}0.68 & 0.08 \\ -0.58 & 1.67 \\ -0.10 & 0.04\end{array}$

0.08

1.67

0.04

Step 2

Time 1 Relationship Satisfaction

Condition

Importance

Importance $\mathrm{x}$ Condition

$\begin{array}{ccc}0.67 & 0.08 & 0.60 \cdots \\ 1.65 & 1.50 & 0.16 \\ -0.05 & 0.05 & -0.09 \\ -0.11 & 0.07 & -0.27 \text { \# }\end{array}$

38.56 * 0.48

$0.61 \cdots$

$-0.06$

$-0.19 \cdots$

$30.03 * 0.490 .01 \#$

Note: Condition was represented as a dummy variable with the control group serving as the reference group; Estimates of B, SE B, and $\beta$ reflect Step 2 of the model; \# $\mathrm{p} \leq .10^{*} ; \mathrm{p} \leq 0.05 ;{ }^{* * \mathrm{p}} \leq 0.01 ;{ }^{* * *} \mathrm{p} \leq 0.001$ 

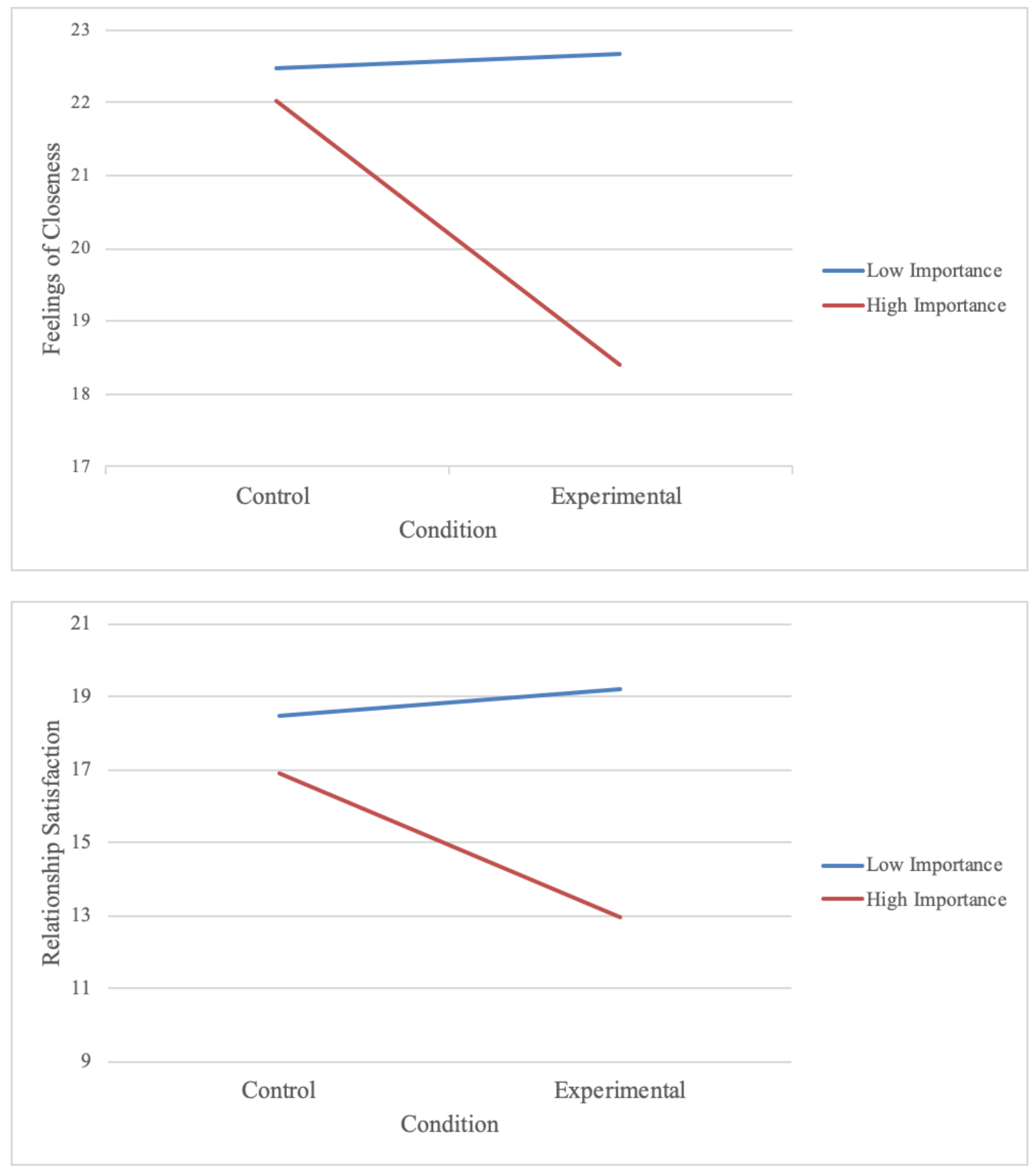

Figure 1. The relationship between condition and Time 2 relationship variables, after controlling for respective Time 1 relationship variables. High and low importance was operationalized as a score of one standard deviation or more above and below the mean, respectively. 